\title{
Prevalence, Risk Factors and Impact of Voice Disorders among Primary School Teachers in Cairo, Egypt
}

\author{
Mona A. Abdel-Hamid, Viviane F. Fahmy, Mohamed A. Momen, Elsayed E. Elokda
}

Community, Environmental and Occupational medicine Department, Faculty of Medicine, Ain Shams University, Cairo, Egypt

Received: May, 2018 Accepted: September, 2018

\begin{abstract}
Background: Teachers are at high risk to develop voice disorders (VDs) due to high vocal demands, which affect their professional life, their mental, physical and emotional state and their ability to communicate. Objective: the aim of the study was to estimate the prevalence rate of VDs among primary school teachers and to identify its risk factors and impact. Method: A cross-sectional study was conducted including 225 primary school teachers. Study tools included an interview questionnaire, Voice Handicap Index and voice ergonomic assessment. Noise levels were recorded. Results: Career prevalence of self-reported vocal problems was $56.4 \%$, year prevalence was $55.1 \%$, and point prevalence was $31.1 \%$. Risk factors of VDs included female gender, high degree of voice loudness, lack of voice rest, use of anticoagulants, laryngeal disease, URTI, asthma and stress. More teachers with VDs had absenteeism, adjusted teaching method and changed overall job opinions. VDs also had negative impact on teachers' physical, functional and emotional state.
\end{abstract}

Key words: Voice disorders; Dysphonia; Teachers; Voice risk factors; Voice Handicap Index.

Corresponding Author: Mona A. Abdel-Hamid

E-mail: m_zahry@med.asu.edu.eg

\section{Introduction}

Teachers have overwhelming vocally demanding requests as they are teaching regularly for long hours in environments with acoustically difficult characteristics in addition to only having brief periods for voice rest. ${ }^{1}$ That's why teachers were found to have a greater risk to develop voice disorders in comparison to other occupations and to the general population. $^{2}$ Vocal dysfunction that develop or exacerbate throughout the course of their teaching career and manifest as symptoms of voice disorders is recognized as one of the most important occupational hazards influencing them. ${ }^{3}$

Primary school teachers are more susceptible to develop vocal health problems in comparison to secondary school teachers. ${ }^{4}$ They differ in the duration of continuous vocal utilization, in the availability of a chance for voice rest, as well as being usually charged by teaching all subjects. ${ }^{5}$

Variable definitions have been suggested for voice health problems. Roy et al. defined self- reported voice disorder as "any time the voice does not work, perform, or sound as it normally should, so that it interferes with communication". Several risk factors contribute to the everyday vocal load in teachers. They include sociodemographic factors, lifestyle factors, occupational factors, psycho-emotional factors, workplace environmental characteristics, in addition to health-related factors. ${ }^{4,6,7}$

Permanent dysphonia can affect teachers' professional performance as it may result in sickness absenteeism and it may even result in ending of their professional career by being reassigned to 
administrative jobs or early retirement. ${ }^{2}$ In addition, it significantly impairs their communicative ability with its drawbacks on their daily activities and their social life. ${ }^{8}$ Epidemiological studies are important in planning specific prevention and treatment programs according to the community needs. Since the teaching environment and approaches, and cultural and socioeconomic viewpoints contrast across nations, thus prevalence and risk factors may vary from one country to another and thus needs to be assessed in each country.

The aim of this study was to estimate the prevalence of voice disorders among primary school teachers in Cairo, Egypt, to identify the associated risk factors and to determine its impact on their professional life, social life and daily activities, and their emotional state.

\section{Method}

An analytical cross-sectional study was conducted during the period from November 2017 to June 2018. It included teachers working in 10 primary schools (8 public and 2 private schools) which were selected by a multistage random sampling technique and were belonging to 5 different educational administrations corresponding to the 4 sectors of Cairo governorate. The sample size was calculated as 200 primary school teachers to produce a two-sided $95 \% \mathrm{CI}$ with a width equal to 0.15 when the sample proportion is 0.50 (i.e., a 95\% CI of the prevalence $42.5 \%-57.5 \%){ }^{9}$ Accordingly, the study sample included 225 full-time primary school teachers of both sexes and all age groups who were involved in active teaching profession for at least one year. Part time teachers and those who were more involved in administrative activities were excluded from the study.

A predesigned structured selfadministered questionnaire based on the results of previous studies ${ }^{6,10}$ was used to collect data about sociodemographic characteristics, occupational history, workplace environmental characteristics (classroom humidity, dust level, cleanliness and aeration), voice disorders and other health related factors and impact of voice problems on their professional life.

Prevalence of voice disorders among primary school teachers was estimated by 3 prevalence rates of self-reported vocal problems. ${ }^{10}$ Career prevalence defined as the frequency of voice problems during the person's entire teaching career. A teacher was considered having a vocal problem if he or she mentioned that vocal problems occurred twice a year or more frequently during his or her teaching career. Teaching year prevalence defined as the frequency of voice problems during the current teaching year (2017-2018). A teacher was defined as having a vocal problem if he or she experienced vocal problems every 2 to 3 months or more frequently during the current teaching year. Point prevalence defined as the presence of a self-reported voice problem on the day of the survey.

Teachers were classified into 2 groups; teachers having voice disorders (VD) and teachers with no voice disorders (NVD) based on the career prevalence and/or the teaching year prevalence.

Assessment of the voice ergonomic risk factors in classrooms was performed by using the voice ergonomic assessment in work environment handbook and checklist (VEAW checklist) ${ }^{11}$ in a total of 21 classrooms from the selected schools. If the assessed factor carried no risk and the condition was complied with the recommendation given in the VEAW checklist, the finding was scored zero. If the condition did not comply with the recommendation, the finding was scored one.

The Arabic version of Voice Handicap Index (VHI- Arab) was also used. It was developed and validated by Jacobson et al. ${ }^{12}$ and has been translated into diverse 
languages including Arabic language. ${ }^{13}$ It is a 30-item self-administered questionnaire that is grouped into 3 subscales to assess the functional, emotional, and physical aspects of voice disorders. Each subscale consists of 10 statements. The answers for each statement are scored on a five-point scale. The functional domain statements describe the impact of a person's voice disorders on his or her daily activities; the emotional domain indicates the patient's affective responses to a voice disorder and the physical domain statements represent the self-perceptions of laryngeal discomfort and voice output characteristics. ${ }^{14}$

A sound level meter (Testo 15) was used to measure indoor noise levels in 36 classrooms (6 classrooms in 6 schools, one classroom per grade). It was placed in the middle of the classroom corresponding to the ear height of the seated children ${ }^{15}$ and care was taken not to disrupt the teacher's work, and not to distract students to obtain representative measurements. Measurements were conducted twice during the scholastic day between 9-10 AM in the morning and 12-1 PM in the afternoon ${ }^{16}$. Three measurements were taken at a time with intervals of at least 30 seconds over a five minutes period adding up to six measurements per classroom. A mean of sound level was calculated to represent the overall noise level of the classroom itself and for the whole school.

The level of significance adopted was a two-sided P-value $<0.05$ and the confidence level interval for adjusted odds ratios was $95 \%$.

The study received ethical approval (FMASU MS 27/2018) from Ain Shams University Faculty of Medicine Research Ethics Committee. In addition to administrative approvals from the official educational administrations. A verbal informed consent was obtained from all participating teachers after explaining the aim of the study, the expected benefits, the research steps and that the participation in the study was completely voluntary.

\section{Results}

A total of 225 primary school teachers participated in this study. One hundred and fifty $(66.7 \%)$ teachers were recruited from 8 public schools (2 schools from each educational administration).

Overall, $172(76.4 \%)$ female teachers and $53(23.6 \%)$ male teachers participated in the study (their mean age was $42.4 \pm 8.8$ years). About $81.3 \%$ of the teachers were married and $96 \%$ of them live in Cairo. Only $7.6 \%$ of the teachers were smokers where $46.2 \%$ of them smoke more than 15 cigarettes per day for an average duration of 24.8 years.

The mean number of students per class was $34.43 \pm 8.57$. The mean area of classrooms was of $28.2 \pm 9.07 \mathrm{~m}^{2}$. Regarding voice ergonomic risk factors, it was found that inappropriate indoor air quality (IAQ) was observed in $22 \%$ of classes, risky working culture in $59 \%$ of classes, unavailable sound amplifier in $85.7 \%$ of classes and unavailable audiovisual aids in $71.4 \%$. The overall mean noise level inside 36 classrooms from 6 different schools was $72.3 \pm 7.34$ dB.

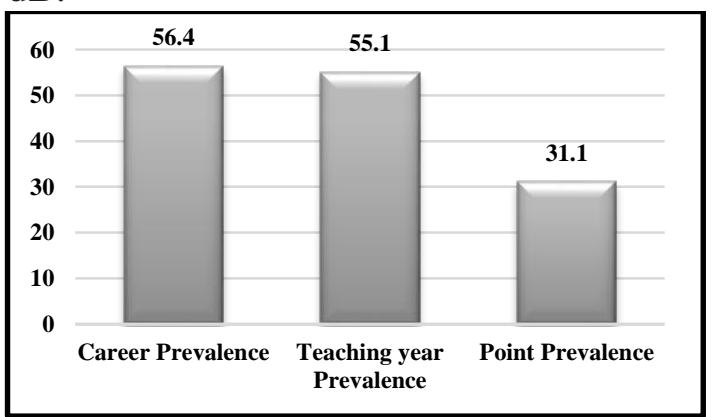

Figure 1: Prevalence of voice disorders

The prevalence of vocal problems reported by teachers during their teaching career (career prevalence) was $56.4 \%$, during the teaching year (year prevalence) was $55.1 \%$ and on the day of the survey (point prevalence) was $31.1 \%$ (Figure 1). 
Table 1: Multiple logistic regression of the risk factors associated with voice health problems among the studied teachers

\begin{tabular}{|c|c|c|c|c|c|c|}
\hline \multirow{2}{*}{\multicolumn{2}{|c|}{$\begin{array}{l}\text { Risk Factors } \\
\text { Sociodemographic characteristics }\end{array}$}} & $\mathbf{B}$ & S.E. & $p$ & $\mathbf{O R}$ & $95 \% \mathrm{CI}$ \\
\hline & & \multicolumn{5}{|c|}{ Sociodemographic characteristics } \\
\hline \multicolumn{2}{|l|}{ Female Gender } & 1.05 & 0.48 & $\mathbf{0 . 0 3}$ & 2.87 & $1.12-7.38$ \\
\hline \multicolumn{7}{|c|}{ Workplace environmental characteristics } \\
\hline \multirow[t]{4}{*}{ Classroom Humidity } & No & & & & 1 & \\
\hline & Slightly & 1 & 0.54 & 0.06 & 2.72 & $0.95-7.8$ \\
\hline & Quite & 1.2 & 0.69 & 0.08 & 3.31 & $0.86-12.73$ \\
\hline & Very & 0.09 & 1.12 & 0.94 & 1.09 & $0.12-9.78$ \\
\hline \multirow[t]{4}{*}{ Dust level in classroom } & Without & & & & 1 & \\
\hline & Some & 0.51 & 0.44 & 0.25 & 1.67 & $0.7-3.98$ \\
\hline & Enough & 0.6 & 0.7 & 0.39 & 1.82 & $0.47-7.12$ \\
\hline & Much & -0.21 & 1.1 & 0.85 & 0.81 & $0.09-6.93$ \\
\hline \multirow[t]{4}{*}{ Noise level in classroom } & Without & & & & 1 & \\
\hline & Some & 1.54 & 1.73 & 0.38 & 4.66 & $0.16-139.2$ \\
\hline & Enough & 0.79 & 1.73 & 0.65 & 2.2 & $0.07-65.67$ \\
\hline & Much & 2.2 & 1.87 & 0.24 & 9.03 & $0.23-352.9$ \\
\hline \multicolumn{2}{|c|}{$\begin{array}{l}\text { Shout as a result of the noise to be made } \\
\text { hear }\end{array}$} & -0.16 & 0.89 & 0.86 & 0.85 & $0.15-4.81$ \\
\hline \multicolumn{7}{|c|}{ Occupational history } \\
\hline \multirow{3}{*}{$\begin{array}{l}\text { Degree of voice loudness } \\
\text { used in the class }\end{array}$} & Low & & & & 1 & \\
\hline & Moderate & 0.75 & 0.96 & 0.43 & 2.12 & $0.32-13.89$ \\
\hline & High & 2.15 & 1.05 & 0.04 & 8.62 & $1.11-67.11$ \\
\hline \multicolumn{2}{|c|}{ Lack of voice rest after the scholastic day } & 0.93 & 0.44 & 0.04 & 2.55 & $1.07-6.06$ \\
\hline \multicolumn{7}{|c|}{ Medical history } \\
\hline \multicolumn{2}{|l|}{ Diagnosed laryngeal disease } & 4.34 & 1.14 & $<0.001$ & 76.55 & $8.25-710.4$ \\
\hline \multicolumn{2}{|l|}{ History of allergy } & -1.42 & 0.83 & 0.09 & 0.24 & $0.05-1.23$ \\
\hline \multicolumn{2}{|l|}{ Diagnosed Nasal / Sinus allergy } & 1.43 & 0.85 & 0.09 & 4.19 & $0.79-22.16$ \\
\hline \multicolumn{2}{|l|}{ Repeated URTI } & 1.19 & 0.41 & 0.004 & 3.28 & $1.46-7.38$ \\
\hline \multicolumn{2}{|l|}{ Asthma } & 2.86 & 1.06 & 0.007 & 17.45 & $2.18-140.4$ \\
\hline \multicolumn{2}{|l|}{ GERD } & 0.1 & 0.61 & 0.89 & 1.11 & $0.34-3.65$ \\
\hline \multicolumn{2}{|l|}{ Stress } & 1.1 & 0.56 & 0.05 & 3 & $1-9.02$ \\
\hline \multicolumn{2}{|l|}{ Anxiety } & 0.04 & 0.58 & 0.95 & 1.04 & $0.33-3.24$ \\
\hline \multicolumn{2}{|l|}{ Hearing impairment } & 0.81 & 0.69 & 0.24 & 2.26 & $0.59-8.69$ \\
\hline \multicolumn{2}{|l|}{ Allergy Medications } & 0.34 & 1.03 & 0.74 & 1.4 & $0.19-10.48$ \\
\hline \multicolumn{2}{|l|}{ Anticoagulants } & 2.81 & 1.32 & 0.03 & 16.54 & $1.26-217.6$ \\
\hline
\end{tabular}


univariate analysis were entered in step one (gender, classroom humidity, dust level in classroom, noise level in classroom, shouting as a result of the noise to be made hear, degree of voice loudness used while teaching, voice rest after the scholastic day, allergy, nasal or sinus allergy, recurrent upper respiratory tract infections (URTI), asthma, GERD, stress, anxiety, hearing impairment and use of antiallergic medications and anticoagulants). Risk factors of voice disorders included female gender $(\mathrm{OR}=2.87, \mathrm{CI}=1.12-7.38)$, high degree of voice loudness $(\mathrm{OR}=8.62, \mathrm{CI}=1.11-$ 67.11), lack of voice rest after the scholastic day $(\mathrm{OR}=2.55, \mathrm{CI}=1.07-6.06)$, laryngeal disease $(\mathrm{OR}=76.55, \mathrm{CI}=8.25-$ 710.4), recurrent URTI $(\mathrm{OR}=3.28$, $\mathrm{CI}=1.46-7.38), \quad$ asthma $\quad(\mathrm{OR}=17.45$, $\mathrm{CI}=2.18-140.4), \quad$ stress $\quad(\mathrm{OR}=3.0$, $\mathrm{CI}=1.0-9.02)$ and anticoagulant drugs $(\mathrm{OR}=16.54, \mathrm{CI}=1.26-217.6)$ (Table 1).

Table 2: Impact of voice health problems on the professional life of the studied teachers

\begin{tabular}{|c|c|c|c|c|c|}
\hline \multirow{2}{*}{$\begin{array}{c}\text { Teachers' professional } \\
\text { life }\end{array}$} & $\begin{array}{c}\text { VD } \\
(\mathrm{N}=127) \\
\end{array}$ & $\begin{array}{c}\text { NVD } \\
(\mathrm{N}=98)\end{array}$ & \multirow{2}{*}{$\chi^{2}$} & \multirow{2}{*}{$\begin{array}{c}\mathrm{P}- \\
\text { value }\end{array}$} & \multirow[t]{2}{*}{ OR $(95 \% \mathrm{CI})$} \\
\hline & No $(\%)$ & No $(\%)$ & & & \\
\hline Sickness absenteeism & $59(86.8)$ & $9(13.2)$ & 36.44 & $<0.001$ & $8.58(3.98-18.52)$ \\
\hline Adjusting teaching method & $86(78.2)$ & $24(21.8)$ & 41.36 & $<0.001$ & $6.47(3.58-11.69)$ \\
\hline $\begin{array}{ll}\text { Changing opinion } & \text { on } \\
\text { teaching profession }\end{array}$ & $72(85.7)$ & $12(14.3)$ & 46.71 & $<0.001$ & 9.38 (4.67-18.87) \\
\hline
\end{tabular}

Boldface values indicate statistical significance $(P<0.05) . V D=$ Voice disorder group, $N V D=$ Non -voice disorder group, $\chi^{2}=$ Chi square test, $O R=$ Odds ratio, $C I=$ Confidence interval.

Regarding the impact of voice health revealed that significantly higher problems on the professional life of the studied teachers, results revealed that higher percentage $(86.8 \%)$ of teachers who took days away from their work due to illness (sickness absenteeism) were having voice disorders $(\mathrm{OR}=8.58, \mathrm{CI}=$ $3.98-18.52)(\mathrm{p}<0.001)$. Moreover, results percentage $(78.2 \%)$ of teachers who had adjusted their teaching method and changed their opinions on teaching profession were those with VD $(\mathrm{OR}=6.47, \mathrm{CI}=3.58-11.69$ and $85.7 \%$, $\mathrm{OR}=9.38, \mathrm{CI}=4.67-18.87$ respectively) $(\mathrm{p}<0.001)$ (Table 2).

Table 3: Voice Handicap Index scores of the studied teachers:

\begin{tabular}{llll}
\hline Voice Handicap Index scores & Mean & SD & Min - Max scores \\
\hline Functional subscale & 6.3 & 6.6 & $0-33$ \\
\hline Physical subscale & 11.9 & 9.1 & $0-38$ \\
\hline Emotional subscale & 4.9 & 7.2 & $0-35$ \\
\hline Total score & 23.04 & 20.8 & $0-99$ \\
\hline
\end{tabular}

$S D=$ Standard Deviation, Min= Minimum, Max = Maximum.

Regarding the teacher's perception of their vocal handicap, the mean total score of voice handicap index was $23.04 \pm 20.8$. The highest mean score was for the physical subscale (11.9 \pm 9.1$)$, followed by the functional subscale $(6.3 \pm 6.6)$, and the least mean score was for the

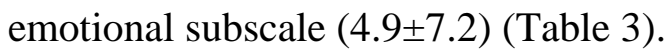

\section{Discussion}

In the current study, it was found that more than three quarters of the studied teachers were females $(76.4 \%)$. This finding agrees with De Jong et al. who declared that there are more female teachers in comparison to male teachers in primary schools. ${ }^{17}$ The overall mean noise level inside classrooms estimated 
in 36 classrooms was $72.3 \mathrm{~dB}$ ranging between $69.58 \mathrm{~dB}$ and $75.27 \mathrm{~dB}$, which largely exceeds the WHO standard requirement of $35 \mathrm{~dB}^{18}$. Nearly similar results were reported by Peng et al. where the mean total noise level was 72 dB. ${ }^{15}$ Alsubaie, in his study among elementary school teachers of Eastern Province, Saudi Arabia, found that the mean noise level was $77.65 \pm 5.49 \mathrm{~dB} .^{16}$

There is a wide variation in the reported prevalence rates of voice disorders, and the comparison between different studies is difficult because of the variability in the definitions of voice problems, in the methodology used and, in the sample size. ${ }^{19}$ The present study used the same prevalence questions, time frame, and definition of a voice problem used in a frequently cited South Australian study. ${ }^{9}$ Three prevalence rates of self-reported voice symptoms were estimated, based on three different time periods. The career prevalence of voice disorders among the studied primary school teachers in the current study was higher than that of Russell et al. (56.4\% versus $19 \%)^{10}$, which may be due to differences in duration of teaching careers or classroom environmental conditions, lack of vocal hygiene awareness among Egyptian teachers compared to the Australian ones, or sociodemographic differences between both samples. However, the high teaching career prevalence rate of voice disorders found in the current study agrees with other studies as Roy et al. $(58 \%)^{1}$, Kooijman et al. $(58.6 \%)^{20}$ and Seifpanahi et al. $(54.6 \%) .{ }^{21}$ On the other hand, higher career prevalence was reported by a Brazilian study $(87.3 \%){ }^{22}$ Year prevalence of voice disorders was also higher than that reported by Russell et al. $(55.1 \%$ versus $20 \%) .{ }^{10}$ However, it is consistent with that reported in a study conducted in Bintulu, Sarawak $(53.8 \%){ }^{23}$ Point prevalence of voice disorders was also higher than that reported by Russell et al. (31.1\% versus
$16 \%)^{10}$, however it agrees with Seifpanahi et al. who reported a point prevalence of $33.6 \% .^{21}$ Other studies reported lower point prevalence as De Jong et al. and Sala et al. (18\% and 17\% respectively). ${ }^{5,17}$ The lower prevalence in the later studies can be explained by the different methodologies used. In Sala's study, the authors clinically assessed the teachers for the presence of laryngitis whereas the current study used a questionnaire and evaluated the selfperceived vocal complaints. ${ }^{5}$

The finding that female teachers experienced more voice problems than their male colleagues is consistent with many previous studies. ${ }^{17,19,24}$ It has been hypothesized that women are more prone to develop voice disorders due to specific physiological characteristics of their larynx. They have shorter vocal cords resulting in speaking with a higher fundamental frequency. ${ }^{1}$ In addition, their vocal folds have lower concentrations of hyaluronic acid in the superficial layer than that in the deeper layers of the lamina propria while men have a homogenous distribution throughout their vocal folds. This results in a less available tissue-dampening mass and a lower shock-absorbing capacity, thus less protection from the vibratory trauma of phonation and less effectiveness for wound repair ${ }^{25}$. However, despite of the above mentioned epidemiological and physiological evidences, Munier and Kinsella failed to find significant gender differences. ${ }^{4}$

According to the current study results, talking loudly in class was considered as a risk factor of voice disorders among primary school teachers. These abusive vocal behaviors increase the frequency of vocal symptoms and are considered as a risk factor for voice disorders as declared by Laukkanen et al. ${ }^{26}$ The vocal loading increases on speaking in high background noise as the speaker has to raise the loudness level to convey his message clearly. Such increase in 
loudness level will further increase the medial compression of the vocal folds leading to higher mechanical load on the vocal fold tissue which may increase the risk of vocal fatigue. ${ }^{27}$

Lack of voice rest after the scholastic day was also proved to be a risk factor. This result is consistent with previous studies among elementary school teachers who reported that on exposure to noisy environments and stressful situations, teachers strain their voice for long durations and do not have enough time to rest or recover it. ${ }^{1,5}$

Recurrent URTI, asthma and diagnosed laryngeal disease were found to be significant risk factors for voice disorders among primary school teachers. These findings confirm results of Devadas et al. who found a significant relationship between voice disorders and respiratory problems in teachers. ${ }^{28}$ Moreover, Roy et al. reported that voice problems are more common in teachers suffering from respiratory allergies, asthma, and chronic upper respiratory illnesses. ${ }^{1}$ Upper respiratory tract infections can lead to hoarseness or even complete voice loss due to laryngitis which if combined with continuous voice use results in vocal cords inflammation and may impair voice production. This in turn may require more effort to convey the message in the classroom resulting in vocal fatigue. ${ }^{29}$

Regarding psychological stress as a risk factor of voice disorders, several studies confirms this result., ${ }^{2,6.28}$ Stress affects voice production and progression of dysphonia as it is thought to cause hypercontraction of intrinsic and extrinsic laryngeal muscles usually accompanying dysphonia ${ }^{30}$. Furthermore, psychological stress may increase the self-perception of the vocal load in teachers and may lead to change in phonation. ${ }^{29}$

Anticoagulants may increase chances of vocal cord hemorrhage or polyp formation in response to trauma ${ }^{31}$ which agrees with the current study result that the use of anticoagulants is a risk factor of voice disorders among primary school teachers.

Results revealed no significant association between use of asthma medications and voice problems. However, a previous study reported that corticosteroids inhalation is one of the possible causes of vocal problems by causing laryngeal irritation. ${ }^{32}$

Regarding the impact of voice disorders on the professional life of teachers, the majority of teachers who took days away from their work were those having voice disorders which indicates a strong association between voice disorders and sickness absenteeism as confirmed by Alva et al. ${ }^{33}$ The drawbacks of taking days away from work are huge. It results in a considerable cost to the education system in terms of lost teaching days and educational outcomes, which in turn have a negative impact on student achievement. $^{34}$

It was also found that higher percentage of teachers who had adjusted their teaching method were those having voice disorders, indicating a strong relationship between voice disorders and job performance. A voice problem may also cause physical discomfort and pain, which results in teacher's disappointment and restricts his/her professional activities. ${ }^{35}$ This reduction in teaching activities by the dysphonic teachers may affect the students' learning achievement. ${ }^{5}$

It was also found that teachers having voice problems were changing their overall job opinions and thinking of early retirement more than their colleagues not having voice problems. This result agrees with Alva's et al. who reported that $14.8 \%$ of the teachers with voice disorders had changed their opinions on the teaching profession and $7.4 \%$ reported the chance for early retirement. ${ }^{33}$ 
The Voice Handicap Index (VHI) is a tool used to assess the perception of vocal handicap among teachers regardless of the physical condition of their larynx. In this study, the mean total score of VHI was $23.04 \pm 20.8$. In comparison to studies performed in other Arab countries, this result is consistent with a recent Jordanian study where the mean score was 20.37. ${ }^{36}$ However, it was higher than other more recent studies conducted in Kuwait and United Arab Emirates (16.83 and 14.38 respectively). ${ }^{37,38}$

Physical subscale of VHI had the highest score, which agrees with Kooijman et al. ${ }^{20}$ This indicates that physical aspects of voice problems have the greatest impact on psychosocial functioning. The mean score of the functional subscale of VHI was $6.3 \pm$ 6.6. Comparing to previous studies in Arab countries, it was almost similar to Albustan et al. (6.38 \pm

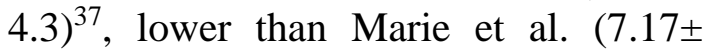
$4.9)^{36}$ and higher than Natour et al. $(4.94 \pm 4.24){ }^{38}$

The least mean score was the emotional subscale $(4.9 \pm 7.2)$. it was also the lowest among other recent studies; 4.99 in Jordan ${ }^{36}, 3.73$ in Kuwait $^{37}$ and 3.15 in United Arab Emirates. ${ }^{38}$

\section{Conclusion}

Teaching is a high-risk profession for developing VDs where a high prevalence of vocal disorders was observed associated with multiple risk factors. VDs have negative impact on teachers' professional life and their physical, functional and emotional state.

\section{References}

1. Roy N, Merrill RM, Thibeault S, Parsa RA, Gray SD, Smith EM. Prevalence of voice disorders in teachers and the general population. J Speech Lang Hear Res. 2004; 47(2):281-93.

2. Behlau M, Zambon F, Guerrieri AC, Roy N. Epidemiology of voice disorders in teachers and nonteachers in Brazil: prevalence and adverse effects. J Voice. 2012; 26: 665.e9-665.e18.

3. Johnson KJ, Akinola MA, Okonkwo KC. The Prevalence of Voice Disorders in Secondary School Teachers in South west Nigeria; 2017; 16(2): 76-9.

4. Munier C, Kinsella R. The prevalence and impact of voice problems in primary school teachers. Occup Med. 2008; 58:74.

5. Sala E, Laine A, Simberg S, Pentti J, Suonpaa J. The prevalence of voice disorders among day care center teachers compared with nurses: a questionnaire and clinical study. J Voice. 2001; 15:413-23.

6. Chen SH, Chiang S-C, Chung Y-M, et al. Risk factors and effects of voice problems for teachers. J Voice. 2010; 24:183-92.

7. Charn TC, Mok PK. Voice problems amongst primary school teachers in Singapore. J Voice. 2012;141-7.

8. Luce F, Teggi R, Ramella B, et al. Voice disorders in primary school teachers. Acta Otorhinolaryngol Ital. 2014; 34:412-8.

9. De Bodt MS, Wuyts FL, Van de Heyning PH, Lambrechts L, Vanden Abeele D. Predicting vocal outcome by means of a vocal endurance test: a 5-year follow-up study in female teachers. Laryngoscope. 1998;108(9): 1363-7.

10. Russell A, Oates J, Greenwood KM. Prevalence of voice problems in teachers. J Voice. 1998; 12:467-79.

11. Sala E, Hellgren U, Ketola R, Laine L, Olkinuora P, Rantala L, Sihvo M. Voice Ergonomic Screening in Work Environment-Handbook and Checklist [in Finnish and Swedish]. Helsinki, Finland: The Finnish Institute of Occupational Health; 2009.

12. Jacobson BH, Johnson A, Grywalski C, Silbergleit A, Jacobson G, Benninger MS, et al. The Voice Handicap Index (VHI): development and validation. Am J Speech Lang Pathol. 1997; 6:66-70.

13. Saleem AF, Natour YS. Standardization of the Arabic version of the Voice Handicap Index: an investigation of validity and reliability. Logoped Phoniatr Vocol. 2010; 35:183-8.

14. Malki KH, Mesallam TA, Farahat M, Bukhari M, Murry T. Validation and cultural modification of Arabic voice handicap index. Eur Arch Otorhinolaryngol 2010; 267:174351. 
15. Peng J, Zhang H, Wang D. Measurement and analysis of teaching and background noise level in classrooms of Chinese elementary schools. Applied Acoustics. 2018; 131:1-4.

16. Alsubaie ASR. Indoor Noise Pollution in Elementary Schools of Eastern Province, Saudi Arabia. 2014; 3(1):25-9.

17. De Jong FI, Kooijman PG, Thomas G, et al. Epidemiology of voice problems in Dutch teachers. Folia Phoniatr Logop. 2006; 58:186-98.

18. Fidêncio VLD, Moret ALM, Jacob RTS. Measuring noise in classrooms: a systematic review. CoDAS. 2014; 26:155-8.

19. Leao SHD, Oates JM, Purdy SC, Scott D, Morton RP. Voice Problems in New Zealand Teachers: A National Survey. Journal of Voice. 2015; 29(5): 645.e1645.e13.

20. Kooijman PG, Thomas G, Graamans K, et al. Psychosocial impact of the teacher's voice throughout the career. J Voice. 2007; 21:316-24.

21. Seifpanahi S, Izadi F, Jamshidi AA, Torabinezhad F, Sarrafzadeh J, Sobhani-Rad $\mathrm{D}$, et al. Prevalence of Voice Disorders and Associated Risk Factors in Teachers and Nonteachers in Iran. Journal of Voice. 2016; 30(4):5.

22. Alves LP, Araujo LTR, Xavier Neto JA. Prevalence of vocal complaints and study of associated factors in a sample of elementary school teachers in Maceio, Brazil. Rev Bras Saude Ocup. 2010; 35:168-75.

23. Inja R, Abdul Rahman H. Prevalence of voice disorder among primary school teachers in Bintulu, Sarawak. 2016; 89-98.

24. Trinite B. Epidemiology of Voice Disorders in Latvian School Teachers. Journal of Voice. 2017; 31(4): 508.e1508.e9.

25. Ward PD, Thibeault SL, Gray SD. Hyaluronic acid: its role in voice. $\mathrm{J}$ Voice. 2002; 16:303-9.

26. Laukkanen AM, Ilomaki I, Leppanen K, Vilkman E. Acoustic measures and selfreports of vocal fatigue by female teachers. $\mathrm{J}$ Voice. 2008; 22:283-9.

27. Jónsdottir V, Laukkanen AM, Vilkman E. Changes in teachers' speech during a working day with and without electric sound amplification. Folia Phoniatr Logop. 2002; 54:282-7.

28. Devadas U, Bellur R, Maruthy S. Prevalence and Risk Factors of Voice Problems Among Primary School Teachers in India. Journal of Voice. 2017; 31(1): 117.e1-117.e10.

29. Simberg S, Sala E, Tuomainen J, et al. Vocal symptoms and allergy - a pilot study. J Voice. 2009; 23:136-9.

30. Simberg S, Sala E, Vehmas K, et al. Changes in the prevalence of vocal symptoms among teachers during a twelveyear period. J Voice. 2005; 19:95- 102.

31. Neely JL, Rosen C. Vocal fold hemorrhage associated with coumadin therapy in an opera singer. J Voice 2000; 14:272-7.

32. Bhalla RK, Jones AS, Roland NJ. Prevalence of pharyngeal and laryngeal complications in adult asthmatics using inhaled corticosteroids. J Laryngol Otol. 2008; 122:1078-83.

33. Alva A, Machado M, Bhojwani K, Sreedharan S. Study of Risk Factors for Development of Voice Disorders and its Impact on the Quality of Life of School Teachers in Mangalore, India. Journal of clinical and diagnostic research: JCDR. 2017; 11(1):1-5.

34. Araujo TM, Reis EJFB, Carvalho FM, Porto LA, Reis IC, Andrade JM. Factors associated with voice disorders among women teachers. Cad Saude Publica. 2008; 24:1229-38.

35. Rodrigues G, Zambon F, Mathieson L, Behlau M. Vocal tract discomfort in teachers: its relationship to self-reported voice disorders. J Voice. 2013;27: 473-80.

36. Marie B, Natour Y, Haj-Tas M. Jordanian teachers' perceptions of voice handicap. Logoped Phoniatr Vocol. 2014; 39:81-6.

37. Albustan SA, Marie BS, Natour YS, Darawsheh WB. Kuwaiti Teachers' Perceptions of Voice Handicap. Journal of Voice. 2018; 32(3):319-324.

38. Natour Y, Sartawi A, Al Muhairi O, et al. Emirati teachers' perceptions of voice handicap. J Voice. 2015; 30: 378.e13378.e20. 